\title{
Phosphor Converted White Led with Improved CRI
}

\author{
P. J. Yadav ${ }^{1}$, N. D. Meshram², C. P. Joshi' ${ }^{3}$, S. V. Moharil ${ }^{4}$ \\ ${ }^{1}$ Kamla Nehru Mahavidyalaya, Sakkardara, Nagpur, India \\ ${ }^{2}$ Shri Mathuradas Mohota College of Science, Sakkardara, Nagpur, India \\ ${ }^{3}$ Physics Department, Shri Ramdeobaba K. N. Engineering College, Nagpur, India \\ ${ }^{4}$ Department of Physics, R.T.M. Nagpur University, Nagpur, India \\ Email: yadav.pooja75@yahoo.in
}

How to cite this paper: Yadav, P.J., Meshram, N.D., Joshi, C.P. and Moharil, S.V. (2018) Phosphor Converted White Led with Improved CRI. Journal of Applied Mathematics and Physics, 6, 657-662. https://doi.org/10.4236/jamp.2018.64058

Received: January 5, 2018

Accepted: April 9, 2018

Published: April 12, 2018

\begin{abstract}
Most of the commercial white LED lamps use blue chip coated with yellow emitting phosphor. YAG: $\mathrm{Ce}^{3+}$ phosphor is coated on blue chip to obtain white light. Though this is commercially successful, there are several drawbacks such as "halo effect", poor colour rendition, etc. In recent years several efforts have been made to improve LED lamp performance. In this paper modification of YAG:Ce phosphor for improving CRI, by introducing $\mathrm{Gd}^{3+}, \mathrm{Pr}^{3+}$ or $\mathrm{Tb}^{3+}$ at $\mathrm{Ce}^{3+}$ site is reported.
\end{abstract}

\section{Keywords}

YAG, Phosphors, White LED, CRI and Commercial Phosphor etc.

\section{Introduction}

Solid state lighting based on high-brightness LEDs has emerged as a new potentially revolutionary technology that could save up to half the energy used for lighting applications. Compared with the traditional lighting, white LED has the following advantages; small (use of many kinds of associations and flexible array device), robust, long lifetime (more than 10,000 hours), low power consumption and low pollution. Thus, White LED would be the most important light source in the $21^{\text {st }}$ century [1].

White LEDs, based on blue LED chips coated with a yellow emitting phosphor (YAG:Ce), were first reported in 1997 [2]. The blue chip/YAG:Ce system has many advantages. But the lamps fabricated in this manner give a poor colour rendering because the resulting light is typically deficient in the green and red colours. There are two approaches which are being followed to overcome this 
problem. In the first approach, white LEDs are made by coating near ultraviolet (n-UV) emitting LED with a mixture of high efficiency red, green and blue emitting phosphors [3], analogous to the fluorescent lamp. This method yields lamps with better colour rendition. Addition of a yellow emitting phosphor improves colour rendition index (CRI) further. Recently, much progress has been made for the emission efficiency of LED chips in the near UV-to-deep blue range [4] [5] [6] [7]. However, cost and light output wise, near UV chips are much inferior to blue chips. Thus, the second approach [8] comprising of coating blue excitable, green and red phosphors on blue chip, is considered to be more practicable for the time being. At present, LED lamps with YAG:Ce phosphor coated on the blue chip are dominating the market. In this paper modification of YAG:Ce phosphor for improving CRI, by introducing $\mathrm{Gd}^{3+}, \mathrm{Pr}^{3+}$ or $\mathrm{Tb}^{3+}$ at $\mathrm{Ce}^{3+}$ site is reported.

\section{Experimental}

Instead of the conventional solution combustion synthesis, we used the modified procedure which led to the formation of the desired compounds in a single step. Reagent grade (Indian Rare Earths, Ltd.) rare earth oxides/carbonates were converted to the corresponding nitrates by dissolving in nitric acid. The nitrates were dried by prolonged, gentle warming. Stoichiometric amounts of hydrated nitrates of yttrium, aluminium and cerium were thoroughly mixed with urea/ glycine. The nitrate to fuel ratios were calculated by the method described earlier [9] [10]. Table 1 gives the details of the ingredients used in syntheses of various phosphors.

Due to the presence of large water of crystallization in aluminium nitrate, a thick paste was formed. A china dish containing the paste was inserted in a furnace preheated to $500^{\circ} \mathrm{C}$. Within minutes the paste foamed and a flame was produced which lasted for several seconds. The china dish was immediately removed from the furnace. X-ray diffraction patterns were recorded on Philips PANalytical X'pert Pro diffractometer. PL characteristics in the range of 200 $700 \mathrm{~nm}$, at room temperature were studied using a Hitachi F-4000 spectrofluorimeter, with $1.5 \mathrm{~nm}$ spectral slit width.

Table 1. Combustion mixtures used in preparation of various phosphors.

\begin{tabular}{ccccccccc}
\hline \multirow{2}{*}{ Sr. No. } & Composition & \multicolumn{5}{c}{ Ingredients mol ratios } & CRI \\
\cline { 3 - 7 } & & $\mathrm{YN}:$ & $\mathrm{CeN}:$ & $\mathrm{Tb} / \mathrm{Gd} / \mathrm{PrN}$ : & AlN: & Glycine: & Urea & \\
\hline 1 & $\mathrm{Y}_{3} \mathrm{Al}_{5} \mathrm{O}_{12}$ & $3.0:$ & $0:$ & $0:$ & $5:$ & $5:$ & 12.5 \\
2 & $\mathrm{Y}_{2.979} \mathrm{Ce}_{0.021} \mathrm{Al}_{5} \mathrm{O}_{12}$ & $2.985:$ & $0.015:$ & $0:$ & $5:$ & $5:$ & 12.5 & $65-70$ \\
3 & $\mathrm{Y}_{2.964} \mathrm{Ce}_{0.021} \mathrm{Pr}_{0.015} \mathrm{Al}_{5} \mathrm{O}_{12}$ & $2.964:$ & $0.021:$ & $0.015:$ & $5:$ & $5:$ & 12.5 & $78-81$ \\
4 & $\mathrm{Y}_{2.879} \mathrm{Ce}_{0.021} \mathrm{Gd}_{0.100} \mathrm{Al}_{5} \mathrm{O}_{12}$ & $2.879:$ & $0.021:$ & $0.100:$ & $5:$ & $5:$ & 12.5 & $77-82$ \\
5 & $\mathrm{Y}_{2.179} \mathrm{Ce}_{0.021} \mathrm{~Tb}_{0.800} \mathrm{Al}_{5} \mathrm{O}_{12}$ & $2.179:$ & $0.021:$ & $0.800:$ & $5:$ & $5:$ & 12.5 & $77-82$ \\
\hline
\end{tabular}

$\mathrm{YN} \rightarrow \mathrm{Y}\left(\mathrm{NO}_{3}\right)_{3} .6 \mathrm{H}_{2} \mathrm{O}, \mathrm{Ce} / \mathrm{Tb} / \mathrm{Gd} / \mathrm{PrN} \rightarrow \mathrm{Ce} / \mathrm{Tb} / \mathrm{Gd} / \mathrm{PrN}\left(\mathrm{NO}_{3}\right)_{3} .6 \mathrm{H}_{2} \mathrm{O}, \mathrm{AlN} \rightarrow \mathrm{Al}\left(\mathrm{NO}_{3}\right)_{3} .9 \mathrm{H}_{2} \mathrm{O}$. 
The phosphor ( $3 \mathrm{wt} . \%$ ) was dispersed in a transparent silicone resin (Wells Electronic Materials Company, 5012-2A and 5012-2B), and LED was then fabricated by coating the blue LED chip (CREE $458 \mathrm{~nm}, 300$ micron) with the epoxy resin. The electroluminescence (EL) spectra, colour temperature, CIE chromaticity coordinates, CRI and lumen output at room temperature were measured using a $300 \mathrm{~mm}$ integrating sphere and lumen meter (Hangzhou Zhongwei Photoelectricity Company ZVision ZW 3900). The measurements were carried out at $3.2 \mathrm{~V}, 20 \mathrm{~mA}$.

\section{Results and Discussion}

Yang et al. [11] prepared YAG using combustion synthesis with urea as a fuel. However, the combustion product was admixture of YAG and YAP. Repeated sintering for $5 \mathrm{hrs}$ at $1000 \mathrm{C}$ was necessary to obtain YAG. More or less similar results were obtained by Pan et al. [12]. Fu et al. [13] used carbohydrazide fuel, but annealing at $1150 \mathrm{C}$ for 6 hours was required to achieve good crystallinity and PL intensity. In our experiments, when urea was used as a fuel, the combustion products were poorly crystallized. Yttrium nitrate does not have exothermic reaction with urea. Hence we tried mixed (Glycine + urea) fuel. Glycine has exothermic reaction with Yttrium nitrate and urea with aluminum nitrate. XRD pattern of the product obtained with this fuel is shown in Figure 1.

An excellent match is obtained with ICDD file 88 - 2048 corresponding to YAG. No lines corresponding to YAP $(2$ theta $=33.36)$, YAM $(2$ theta $=29.289)$ or YAH ( 2 theta $=32.832$ ) could be seen.

Phase pure YAG is thus obtained in a single step combustion process without any additional thermal treatment when mixed fuel (Glycine + urea) was used. Activation with $\mathrm{Ce}^{3+}$ was also attempted by adding cerous nitrate to the combustion mixture.

Figure 2 shows PL results for the phosphor so prepared. For $465 \mathrm{~nm}$ excitation, intense emission was observed with a broad maximum at $528 \mathrm{~nm}$ and

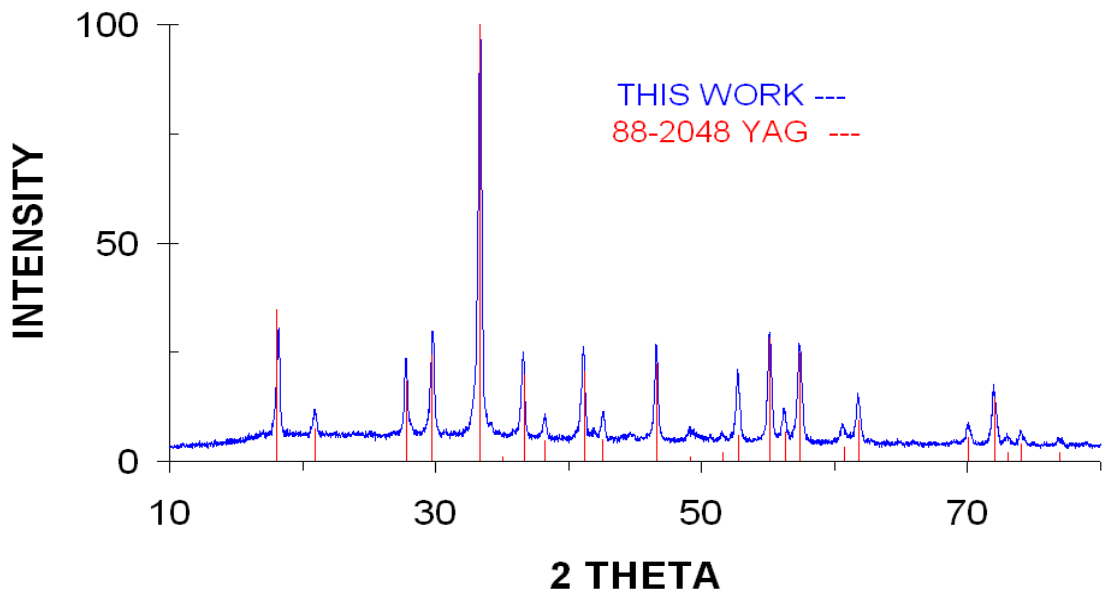

Figure 1. XRD Results for YAG XRD data for YAG is compared with the ICDD data file 88-2048. 


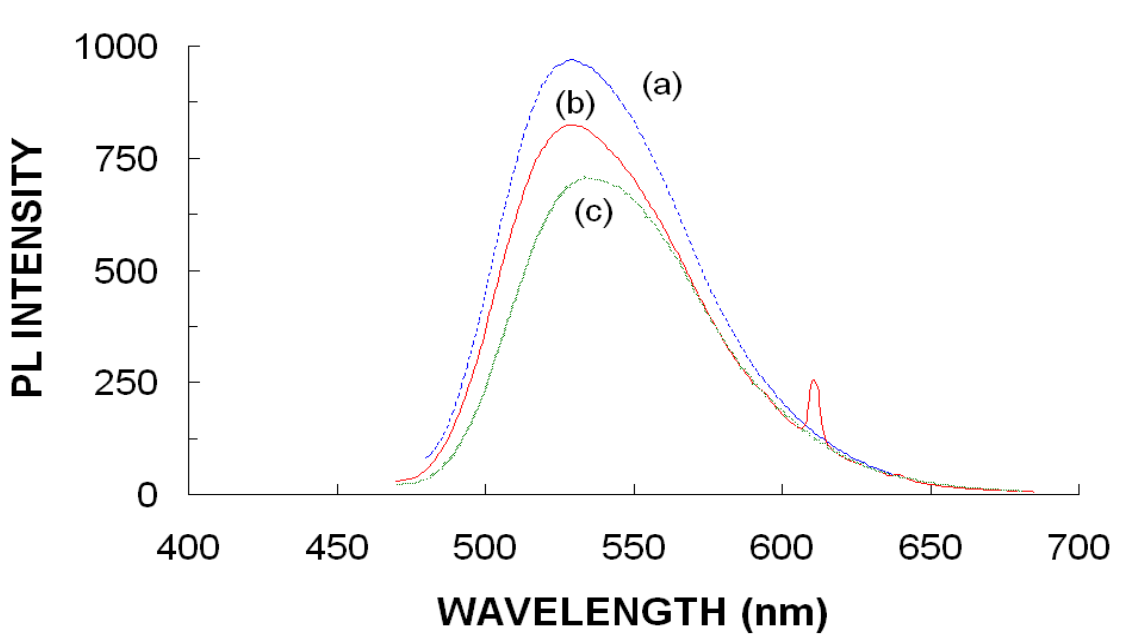

Figure 2. PL spectra for $\mathrm{Ce}^{3+}$ activated (Y, Gd) AG samples a $>$ Excitation for $528 \mathrm{~nm}$ emission of YAG:Ce ${ }^{3+} \mathrm{b}>\mathrm{YAG}: \mathrm{Ce}^{3+}$ Emission for $460 \mathrm{~nm}$ excitation. $\mathrm{Ce}^{3+}$ Emission in $\mathrm{c}>$ $\mathrm{Y}_{2.879} \mathrm{Gd}_{0.100} \mathrm{Ce}_{0.021} \mathrm{Al}_{5} \mathrm{O}_{12}, \mathrm{~d}>\mathrm{Y}_{2.779} \mathrm{Gd}_{0.200} \mathrm{Ce}_{0.021} \mathrm{Al}_{5} \mathrm{O}_{12}$ and $\mathrm{e}>\mathrm{Y}_{2.679} \mathrm{Gd}_{0.300} \mathrm{Ce}_{0.021} \mathrm{Al}_{5} \mathrm{O}_{12}$.

a shoulder around $540 \mathrm{~nm}$ (Figure 2, curve b). This is in excellent agreement with the recent literature results [14]. The excitation spectrum (Figure 2, curve a), consists of several bands; those around 460 and $340 \mathrm{~nm}$ being prominently seen. These positions are also in close agreement with the most of the literature results on YAG:Ce phosphors. Moreover, no emission attributable to YAP or YAM phases was observed.

LEDs fabricated by coating YAG:Ce on blue chip have poor CRI, typically in the range $65-70$. Shifting the spectrum to longer wavelengths or adding red component can improve CRI. Figure 2 shows effect of replacing Y partly by Gd on the emission spectrum. It is seen that with increasing Gd concentration, maxmimum shifts to longer wavelengths. However, intensity also decreases at the same time. Similar effect can be achieved by substituting $\mathrm{Tb}$ at $\mathrm{Y}$ site (Figure 3, curve c).

The shift is related to the lattice expansion caused by substituting smaller $\mathrm{Y}$ ion by bigger rare earth ions. In $\mathrm{Pr}^{3+}$ co-doped sample, there is partial energy transfer from $\mathrm{Ce}^{3+}$ to $\mathrm{Pr}^{3+}$. $\mathrm{Pr}^{3+}$ emission corresponding to ${ }^{3} \mathrm{P}_{\mathrm{o}}-->{ }^{3} \mathrm{H}_{6},{ }^{3} \mathrm{~F}_{2}$ is around $605 \mathrm{~nm}$. $\mathrm{Pr}^{3+}$ co-doping thus adds red component to YAG:Ce PL (Figure 3 , curve b).

Figure 4 shows emission spectra for LEDs fabricated by coating (a) $\mathrm{Y}_{2.879} \mathrm{Ce}_{0.021} \mathrm{Pr}_{0.010} \mathrm{Al}_{5} \mathrm{O}_{12}, \mathrm{Y}_{2.879} \mathrm{Gd}_{0.1} \mathrm{Ce}_{0.021} \mathrm{Al}_{5} \mathrm{O}_{12}$ (b) or $\mathrm{Y}_{2.879} \mathrm{Ce}_{0.021} \mathrm{~Tb}_{0.010} \mathrm{Al}_{5} \mathrm{O}_{12}$ (c) on blue chip. As shown in Table 1, CRI improves considerably compared to that for LED fabricated using YAG:Ce. Colour temperature for all the LEDs is around $6000 \mathrm{~K}$ and colour co-ordinates are typically $0.319,0.326$.

\section{Conclusion}

Using Gd or Tb co-dopants, $\mathrm{Ce}^{3+}$ emission in YAG:Ce could be shifted to longer wavelengths. The shift is due to lattice expansion. On the other hand, co-dopant 


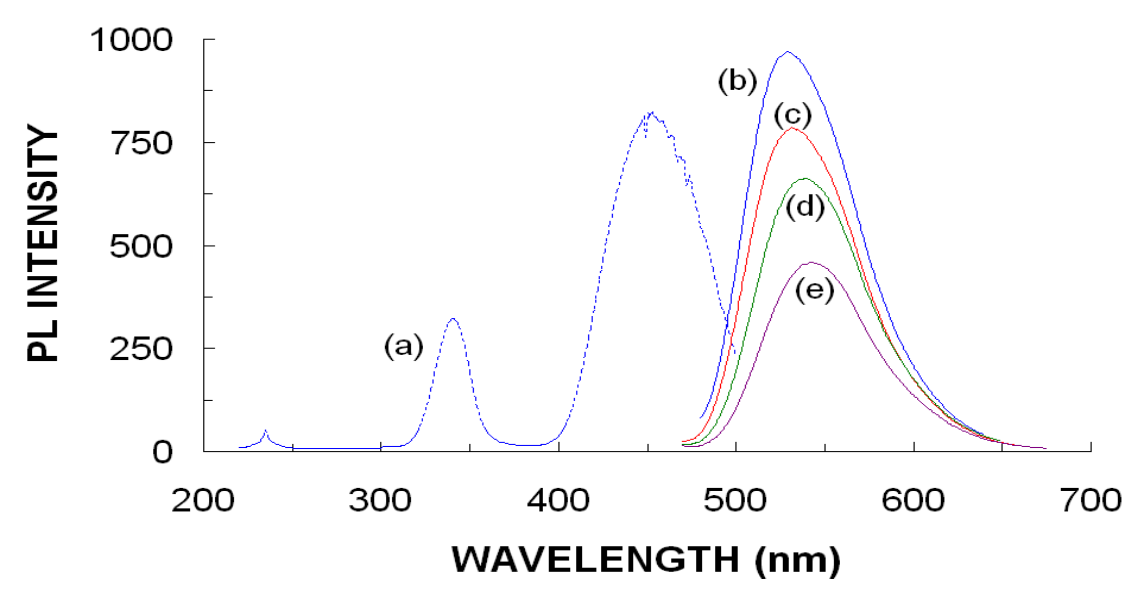

Figure 3. $\mathrm{Ce}^{3+}$ Emission in a $>\mathrm{Y}_{2.979} \mathrm{Ce}_{0.021} \mathrm{Al}_{5} \mathrm{O}_{12}, \mathrm{~b}>\mathrm{Y}_{2.964} \mathrm{Ce}_{0.021} \mathrm{Pr}_{0.015} \mathrm{Al}_{5} \mathrm{O}_{12}$ and $\mathrm{c}>$ $\mathrm{Y}_{2.179} \mathrm{Ce}_{0.021} \mathrm{~Tb}_{0.800} \mathrm{Al}_{5} \mathrm{O}_{12}$.
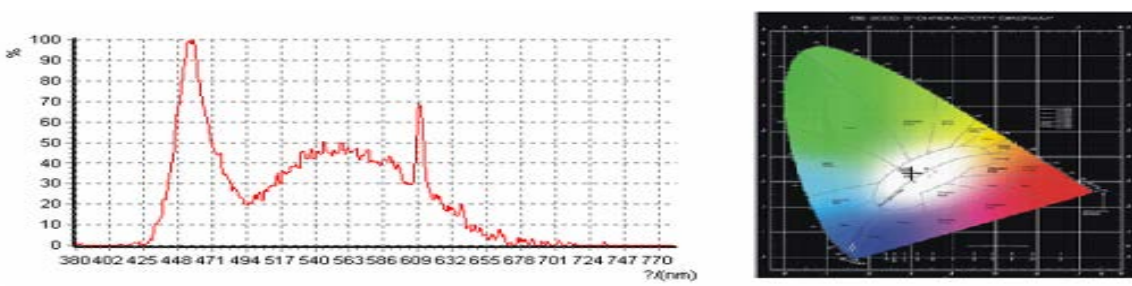

(a)
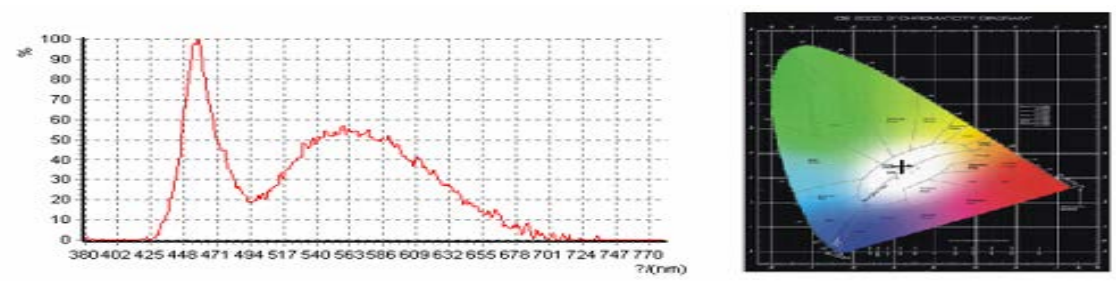

(b)
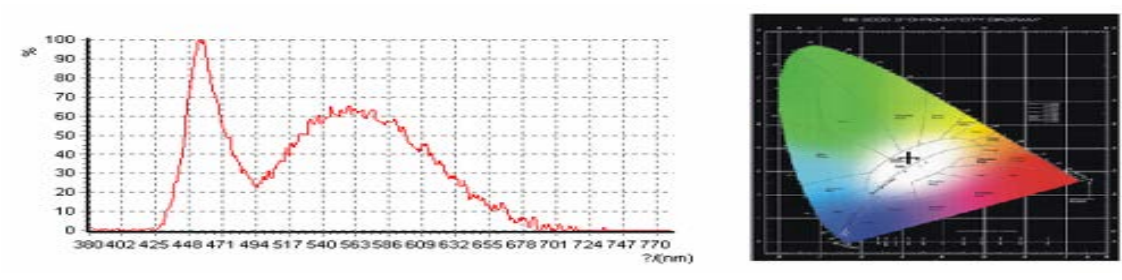

(c)

Figure 4. LED Spectra and colour points for LEDs fabricated from phosphors a > $\mathrm{Y}_{2.964} \mathrm{Ce}_{0.021} \mathrm{Pr}_{0.015} \mathrm{Al}_{5} \mathrm{O}_{12}, \mathrm{~b}>\mathrm{Y}_{2.879} \mathrm{Gd}_{0.100} \mathrm{Ce}_{0.021} \mathrm{Al}_{5} \mathrm{O}_{12}$, and $\mathrm{c}>\mathrm{Y}_{2.179} \mathrm{Ce}_{0.021} \mathrm{~Tb}_{0.800} \mathrm{Al}_{5} \mathrm{O}_{12}$.

$\mathrm{Pr}^{3+}$ results in adding red component to PL emission due to partial energy transfer from $\mathrm{Ce}^{3+}$ to $\mathrm{Pr}^{3+}$. All these modification lead to LEDs with considerably improved CRI.

\section{Acknowledgements}

PJY thanks the Department of Science and Technology, New Delhi for Women Scientist award. 


\section{References}

[1] Zhang, X.M., Park, B., Choi, N., Kim, J., Kim, G.C. and Yoo, J.H. (2009) Mater.lett., 63, 700 .

[2] Nakamura, S. and Fasol, G. (1997) The Blue Laser Diode: GaN Based Light Emitters and Lasers. Spring, Heidelberg.

[3] Xu, Y., Chen, L., Li, Y., Song, G., Wang, Y., Zhuang, W. and Long, Z. (2008) Appl Phys Lett., 92, 021129.

[4] Khizar, M., Fan, Z.Y., Kim, K.H., Lin, J.Y. and Jiang H.X. (2005) Appl Phys Lett, 86, Article ID: 173504.

[5] Chen, L., Lin, C.-C., Yeh, C.-W. and Liu, R.-S. (2010) Materials, 3, 2172.

[6] Xie, R.-J., Hirosaki, N., Li, Y.Q. and Takeda, T. (2010) Materials, 3, 3777.

[7] Ye, S., Xiao, F., Pan, Y.X., Ma, Y.Y. and Zhang, Q.Y. (2010) Mater. Sci. Engg. R, 71, 1.

[8] Shimizu, Y., Sakano, K., Noguchi, Y. and Moriguchi, T. (1999) U.S. Patent 1999; 5998925.

[9] Kingsley, J.J., Suresh, K. and Patil, K.C. (1990) J. Mater. Sci., 251305.

[10] Kingsley, J.J., Manickam, N. and Patil, K.C. (1990) Bull. Mater. Sci., 13, 179.

[11] Yang, Z.P., Li, X., Yang, Y. and Li, X.M. (2006) Proc. SPIE 6033 60330N.

[12] Pan, Y., Wu, M. and Su, Q. (2004) J. Phys. Chem. Solids, 65, 845. https://doi.org/10.1016/j.jpcs.2003.08.018

[13] Fu, Y.-P., Wen, S.-B. and Hsu, C.-S. (2008) J.Alloys.Compd., 458, 318.

[14] Jiao, H., Ma, Q., He, L., Liu, Z. and Wu, Q. (2010) Powder Technology, 198, 229. 